\title{
Effect of Aging on the Electrochemical Performance of LSM-YSZ Cathodes
}

\author{
Baqué, L. C.; Jørgensen, Peter Stanley; Zhang, Wei; Hansen, Karin Vels; Søgaard, Martin
}

Published in:

Journal of the Electrochemical Society

Link to article, DOI:

10.1149/2.0181509jes

Publication date:

2015

Document Version

Peer reviewed version

Link back to DTU Orbit

Citation (APA):

Baqué, L. C., Jørgensen, P. S., Zhang, W., Hansen, K. V., \& Søgaard, M. (2015). Effect of Aging on the Electrochemical Performance of LSM-YSZ Cathodes. Journal of the Electrochemical Society, 162(9), F971F981. https://doi.org/10.1149/2.0181509jes

\section{General rights}

Copyright and moral rights for the publications made accessible in the public portal are retained by the authors and/or other copyright owners and it is a condition of accessing publications that users recognise and abide by the legal requirements associated with these rights.

- Users may download and print one copy of any publication from the public portal for the purpose of private study or research.

- You may not further distribute the material or use it for any profit-making activity or commercial gain

- You may freely distribute the URL identifying the publication in the public portal 


\title{
Effect of aging on the electrochemical performance of LSM-YSZ cathodes
}

\author{
L. C. Baqué, ${ }^{a, *}$, P. S. Jørgensen ${ }^{a}$, W. Zhang ${ }^{a}$, K. V. Hansen ${ }^{a}$, and M. Søgaard ${ }^{a, * *}$ \\ ${ }^{a}$ Department of Energy Conversion and Storage, Technical University of Denmark, \\ Roskilde DK-4000, Denmark
}

\begin{abstract}
Investigations of degradation mechanisms of solid oxide fuel cells are crucial for achieving a widespread commercialization of the technology. In this work, electrochemical impedance spectroscopy (EIS) was applied for studying the aging effect on LSM-YSZ cathodes exposed to humidified air at $900{ }^{\circ} \mathrm{C}$ for up to $3000 \mathrm{~h}$. EIS spectra were fitted by a transmission line model for estimating relevant parameters associated with the LSM/YSZ charge transfer reaction and the oxide ion conduction through the YSZ network. For the reference non-aged sample, the ionic conductivity values are the expected ones for YSZ with $1 \mathrm{eV}$ activation energy and no dependency on oxygen partial pressure $\left(\mathrm{pO}_{2}\right)$, while the charge transfer resistance presents an activation energy of 1.6 $\mathrm{eV}$ and is proportional to $\left(\mathrm{pO}_{2}\right)^{-0.31 \pm 0.08}$. These values agree with those reported in literature, validating the used model. The charge transfer resistance shows no clear tendency with aging time, while the ionic conductivity decreases up to $\sim 79 \%$. Accordingly, the electrochemically active thickness contracts from $60-135 \mu \mathrm{m}$ to $45-60$ $\mu \mathrm{m}$. The changes observed in the cathode transport and electrochemical properties are mostly explained by the evolution of the phases present in agreement with results previously reported in the literature.

*Present address: CONICET-CAB, S. C. de Bariloche (R8402AGP), Argentina

**Present address: Meneta Advanced Shims Technology A/S, Odense N DK-5270, Denmark




\section{Introduction}

Long term stability is a key issue to take into account when considering the commercialization of Solid Oxide Fuel Cells (SOFC). The study of the long term stability of the SOFC components is very important from a technological point of view, since the degradation rate of the fuel cell is determined by the degradation rates of its main components (i.e. cathode, electrolyte and anode). ${ }^{1,2}$

$\mathrm{La}_{1-\mathrm{x}} \mathrm{Sr}_{\mathrm{x}} \mathrm{MnO}_{3-\mathrm{d}}-\left(\mathrm{ZrO}_{2}\right)_{1-\mathrm{y}}\left(\mathrm{Y}_{2} \mathrm{O}_{3}\right)_{\mathrm{y}}(\mathrm{LSM}-\mathrm{YSZ})$ is a widely used composite for SOFC cathodes. The intrinsic degradation mechanisms for LSM-YSZ cathodes reported in literature include the formation of lanthanum and/or strontium zirconates ${ }^{2,3}$, loss of cathode/electrolyte contact ${ }^{3-5}$, cathode coarsening and densification ${ }^{3,4}$, the formation of monoclinic zirconia ${ }^{3}$, and the formation of $\mathrm{Mn}$ oxide and $\mathrm{Mn}$ volatile species at the cathode/electrolyte interface. ${ }^{3,5}$ The degradation mechanisms as well as the degradation rates strongly depend on the cathode composition and the operation conditions (temperature, current density, polarization, oxygen partial pressure $p \mathrm{O}_{2}$, and humidity). The different degradation mechanisms directly affect the different steps involved in the oxygen reduction reaction (ORR) at the cathode, decreasing the electrochemical performance.

Although the ORR at LSM-YSZ cathodes has been extensively investigated in the

last decades, ${ }^{6-13}$ there is not yet a general agreement regarding which mechanisms are involved and which mechanism is the rate limiting step. In order to identify the different contributions to the ORR, electrochemical impedance spectroscopy (EIS) is normally recorded under varying conditions. The ORR steps detected by EIS studies reported in literature include dissociative adsorption of oxygen on the LSM surface ${ }^{8}$ or at the triple 
phase boundary ${ }^{6,9,12}$ (TPB - where electron conducting phase, ionic conducting phase and pores are in contact), diffusion of $\mathrm{O}^{-}$species along the LSM surface to the $\mathrm{TPB}^{6,7,9,11}$, transport of oxygen intermediates and/or oxide ions within the electrode structure (across LSM/YSZ interfaces ${ }^{6,}$ and/or through the YSZ portion of the composite ${ }^{6,9,11,12}$ ), transfer of oxygen intermediates and/or oxide ions at the $\mathrm{TPB}^{6,11,12}$, and oxygen ion transfer to the YSZ electrolyte lattice ${ }^{6-8,10}$. A low frequency contribution related to oxygen gas diffusion in a stagnant gas layer above the electrode structure ${ }^{6}$ or inside the cathode pores ${ }^{9}$ has also been observed at high temperature and low $\mathrm{pO}_{2}$. It is clear that the actual overall ratelimiting mechanisms depend on cathode composition and microstructure, temperature, $p \mathrm{O}_{2}$, polarization, and thermal and electrochemical prehistory. ${ }^{6}$

In many studies, the recorded impedance spectra are fitted using a non-physical model typically based on a combination of a resistor in parallel with a capacitor (R//Q circuit). Subsequently, these are associated with one or more physical processes. However, these circuits cannot properly account for the processes that take place during SOFC operation in cathodes composed by a mixture of an electronic and an ionic conductor such as LSM-YSZ. These phenomena comprise two parallel conduction paths (i.e. electron transport through LSM and oxygen ion transport through YSZ) together with the charge transfer along the LSM/YSZ interface and it is clear that a transmission line model (TLM) approach ${ }^{14,15}$ would seem the most appropriate to describe this kind of phenomena. In fact, it was previously applied in literature to model the EIS response of mixed conducting and composite SOFC electrodes. ${ }^{16-21}$ The TLM allows obtaining the activation energy values for the ionic conductivity and the charge transfer resistance separately, which it is not possible to achieve by modeling the EIS response with R//Q circuits. ${ }^{22}$ It is also useful for estimating the extension of electrochemically active region 
within the electrodes in order to determine its optimal thickness. ${ }^{18}$ Other relevant parameters that can be obtained by the TLM are the conductivity of the ionic conductor phase, the charge transfer resistance, and the charge transfer capacitance. ${ }^{16-21}$ The use of the TLM approach implies the arbitrary assumptions that the ionic conduction and the charge transfer reaction are the rate-determining processes (i.e. discarding other possible limiting steps), and that the electrode is a homogenous phase with effective parameters (i.e. discarding the actual inhomogeneity within the electrode). ${ }^{19}$ Nevertheless, the parameters estimated by using the TLM are comparable to the ones obtained by microstructural models solved with a finite element approach. ${ }^{21,23}$ Accordingly, the use of a transmission line model can give further insight into the long-term performance of the cathode, and even be useful for identifying the degradation mechanisms.

In this work, we have investigated the effect of aging on the electrochemical performance of LSM-YSZ cathodes after exposure to humidified air (4.4\% $\mathrm{H}_{2} \mathrm{O}$ content) at $900{ }^{\circ} \mathrm{C}$ for $3000 \mathrm{~h}$. Cathode conductivity was continuously monitored during the aging treatment using the 4-point van der Pauw technique. The evolution of the cathode electrochemical performance on aged samples was studied by EIS measurements at different temperatures and $\mathrm{pO}_{2}$. The microstructural changes and the phase stability were investigated by scanning electron microscopy (SEM), transmission electron microscopy (TEM) and X-ray diffraction (XRD). The effect of aging on the electrochemical performance and on the transport properties of the cathodes was analyzed by using a transmission line based model. ${ }^{14,15}$ In addition, the degradation and activation mechanisms that affect the cathode performance were identified. 


\section{Experimental}

Samples.- Commercial type composite cathodes were investigated in the present work. These electrodes were composed of a 50:50 vol\% mixture of $\left(\mathrm{La}_{0.8} \mathrm{Sr}_{0.2}\right)_{0.95} \mathrm{MnO}_{3 \pm d}$ (LSM) and $\mathrm{Zr}_{0.85} \mathrm{Y}_{0.15} \mathrm{O}_{1.93}$ (8YSZ) oxides deposited on a $\mathrm{Zr}_{0.94} \mathrm{Y}_{0.06} \mathrm{O}_{1.97}$ (3YSZ) electrolyte and sintered at $1100{ }^{\circ} \mathrm{C}$. A cathode thickness of $50 \mu \mathrm{m}$ and an electrolyte thickness of $140 \mu \mathrm{m}$ were measured by SEM.

The same setup was used to both conduct continuous 4-point van der Pauw measurements on $4.2 \mathrm{~cm} \times 4.2 \mathrm{~cm}$ samples and, at the same time, hold a number of samples with dimensions $0.595 \mathrm{~cm} \times 0.595 \mathrm{~cm}$ for aging. The furnace was cooled down and six $0.595 \mathrm{~cm}$ x $0.595 \mathrm{~cm}$ samples were taken out after $300 \mathrm{~h}, 1000 \mathrm{~h}, 1500 \mathrm{~h}, 2500 \mathrm{~h}$, and $3000 \mathrm{~h}$ of aging followed by reheating the furnace to $900{ }^{\circ} \mathrm{C}$. These $0.595 \mathrm{~cm} \mathrm{x} 0.595$ cm aged samples were then used for the EIS and microstructural characterization including SEM, TEM and XRD. In addition, a fresh non-aged sample (named as $0 \mathrm{~h}$ ) was studied by EIS, SEM and XRD as reference.

Scanning Electron Microscopy.- All samples were mounted into epoxy resin under vacuum and polished with diamond paste down to $0.1 \mu \mathrm{m}$ prior to SEM observations. The cathode microstructure was studied using a FIB/SEM CrossBeam ${ }^{\text {TM }} 1540$ XB (Carl Zeiss AG, Germany) and a 2D FIB imaging protocol in order to achieve contrast between LSM and YSZ. The entire 2D FIB imaging protocol is detailed elsewhere. ${ }^{24}$ Approximately 20 images from each sample were segmented and a range of microstructural parameters were calculated including phase fractions, interface areas between phases, triple phase boundary length and 2D size distributions of pores and solids. 
X-ray Diffraction.- XRD measurements were performed on the LSM-YSZ cathode surface at room temperature using an X-ray diffractometer D8 Advance (Bruker Corporation, Germany) with $\mathrm{Cu} \mathrm{K}_{\alpha}$ radiation and $4 \mathrm{~mm}$ slits. Both aged and non-aged samples were characterized. First, exploratory diffractograms were collected over the $20^{\circ}$ $\leq 2 \Theta \leq 90^{\circ}$ range with $0.02^{\circ}$ step and $0.5 \mathrm{~s} /$ step counting time. No visible peaks were found that indicate reaction between LSM and YSZ phases or the formation of spurious phases. Accordingly, more detailed diffractograms were recorded over the $24^{\circ} \leq 2 \Theta \leq$ $37^{\circ}$ range with $0.02^{\circ}$ step and 5 s/step counting time. Samples were continuously rotated in all experiments to ensure good statistics.

Transmission Electron Microscopy.- The 3000 h aged sample was studied by High Resolution (HR)-TEM. A $100 \mathrm{~nm}$ thin TEM lamella was prepared by a Focused Ion Beam (FIB)-SEM H-bar technique in a FIB/SEM Crossbeam ${ }^{\mathrm{TM}} 1540$ XB (Carl Zeiss AG, Germany) using an optimum method. ${ }^{25}$ A TEM JEM-3000F (Jeol Ltd., Japan) equipped with a field emission gun, operated at $300 \mathrm{kV}$, was employed for microstructure characterization. The point-to-point resolution is $0.19 \mathrm{~nm}$.

Van der Pauw Conductivity Measurements.- The cathode conductivity was continuously monitored over a period of $3000 \mathrm{~h}$ using the 4-point van der Pauw technique. ${ }^{26}$ Measurements were performed on $4.2 \mathrm{~cm} \mathrm{x} 4.2 \mathrm{~cm}$ symmetrical cells at $900{ }^{\circ} \mathrm{C}$ in synthetic air containing $4.4 \% \mathrm{H}_{2} \mathrm{O}$. Synthetic air was obtained by mixing an appropriate ratio of $\mathrm{N}_{2}$ and $\mathrm{O}_{2}$ gases. Four Pt probes were used to contact the top surface of one cathode for each sample and were pressed against the cathode surface by alumina weights. The probes were contacted by Pt wires.

Electrochemical Impedance Spectroscopy. - The oxygen reduction reaction (ORR) was studied by EIS using $0.595 \mathrm{~cm}$ x $0.595 \mathrm{~cm}$ symmetrical cells. EIS measurements 6 
were performed for all samples in dry air between $650{ }^{\circ} \mathrm{C}$ and $850{ }^{\circ} \mathrm{C}$ with $50{ }^{\circ} \mathrm{C}$ steps. In addition, the reference sample and the $1500 \mathrm{~h}$ and $3000 \mathrm{~h}$ aged samples were measured at 650, 750 and $850{ }^{\circ} \mathrm{C}$ under atmospheres with an oxygen partial pressure in the range: 0.006 atm $\leq p \mathrm{O}_{2} \leq 0.21$ atm. The different $p \mathrm{O}_{2}$ were obtained with dry air/ $\mathrm{N}_{2}$ mixtures and monitored with a zirconia oxygen sensor. All impedance spectra were recorded using a frequency response analyzer 1260 (Solartron, UK) within the $4 \times 10^{-3}-10^{6} \mathrm{~Hz}$ frequency range and applying an AC voltage of $50 \mathrm{mV}$ root mean square (rms). Pt current collector layers were painted on both cathodes of each cell and then treated at $900{ }^{\circ} \mathrm{C}$ for 6 hours in stagnant air. Impedance spectra were fitted using the software ZView 3.2c. ${ }^{27}$ Errors of the fitted parameters were estimated by the program as the range of values which gave similar goodness of fit.

\section{Results and Discussion}

Scanning Electron Microscopy. - Figure 1 shows SEM images of the microstructure of the reference and the $3000 \mathrm{~h}$ aged cathodes. Due to the focused ion beam imaging, the dark regions of the image correspond to the LSM phase and the bright regions to the YSZ phase. The intermediate intensity regions correspond to epoxy filled pores. Large LSM grains surrounded by YSZ grains were observed in all the acquired images. Noticeable local variations were observed within each sample. The single image shown for each sample is thus not representative for the entire series of images from that sample, hence the need to analyze a 20 images to obtain values that are representative of the sample. 
Table I summarizes the calculated microstructure parameters for the reference and the aged samples. The calculated values of $l_{\text {TPB }}$ were similar across all aging times, yielding a mean value of $12.4 \mu \mathrm{m}^{-2}$ with a standard deviation of $0.6 \mu \mathrm{m}^{-2}$. Similarly, no significant correlation could be determined between aging times and calculated values for the interface areas, phase fractions and particle size distributions. It is significantly more difficult to obtain high quality images when using the FIB for imaging instead of standard SEM. However, the image related errors are expected to be similar for all samples and the $2 \mathrm{D}$ analysis is thus still useful for detecting changes in measured quantities as a function of aging time. Within the uncertainty, no significant variation with aging time was observed for the microstructural parameters (i.e. triple phase boundary length, interface areas, phase fractions and particle size distributions).

X-ray Diffraction. - Figure 2(a) shows XRD patterns collected at room temperature for the reference and the aged samples. All the main peaks observed in the diffractograms can be indexed as originating from YSZ and LSM phases.

The low intensity peak situated at $2 \Theta \approx 29.4^{\circ}$ and resembling a "hump on the left shoulder" (HLS) ${ }^{28}$ was also found in the 0 h sample (see Figure 2(b)). This feature was proposed to be caused by the anisotropy of lattice distortion, ${ }^{28,29}$ by the formation of a rhombohedral phase induced by stress, ${ }^{30-34}$ by the formation of low-dimensional structures after surface segregation, ${ }^{35}$ and by grinding or polishing. ${ }^{30-32,36}$ As shown in Figure 2(a), the hump is not present in any of the diffractograms corresponding to the aged samples. The shrinking of the HLS after annealing or aging within the $600-1000{ }^{\circ} \mathrm{C}$ range has also been observed by other authors and attributed to a short range ordering of 
oxygen ion vacancies to relax the anisotropy of the lattice distortions, ${ }^{28}$ or to the reverse transformation of the rhombohedral phase. ${ }^{31-33}$

Figure 2 (c) shows a peak at $2 \Theta \approx 28.2^{\circ}$ with $\sim 0.6 \%$ relative intensity in the diffractograms corresponding to the 2500 and $3000 \mathrm{~h}$ aged samples. This peak is related to the formation of small amounts of monoclinic zirconia $\left(\mathrm{m}-\mathrm{ZrO}_{2}\right)$. The $\mathrm{m}-\mathrm{ZrO}_{2}$ formation was also observed by Chen et al. for LSM-YSZ cathodes aged at $1000{ }^{\circ} \mathrm{C}$ in air. $^{37}$

Small quantities of $\mathrm{La}_{2} \mathrm{Zr}_{2} \mathrm{O}_{7}$ (very close to the detection limit) were observed in the reference sample (see Figure 2(d)). The formation of $\mathrm{La}_{2} \mathrm{Zr}_{2} \mathrm{O}_{7}$ would, in principle, not be expected for the $\left(\mathrm{La}_{0.8} \mathrm{Sr}_{0.2}\right)_{0.95} \mathrm{MnO}_{3 \pm \delta}$ cathodes studied in this work. ${ }^{1}$ Nevertheless, Mitterdorfer and Gauckler ${ }^{38}$ have demonstrated that A-site deficient cathodes can retard but not necessarily avoid the formation of $\mathrm{La}_{2} \mathrm{Zr}_{2} \mathrm{O}_{7}$ during sintering. The $300 \mathrm{~h}$ aged sample also contains $\mathrm{La}_{2} \mathrm{Zr}_{2} \mathrm{O}_{7}$ although in a lesser amount than the reference sample, while this phase has not been detected in the diffractograms of the samples aged longer. All the above indicates the decomposition of $\mathrm{La}_{2} \mathrm{Zr}_{2} \mathrm{O}_{7}$ with aging. A similar phenomena was previously reported by other authors. ${ }^{37-39}$

Transmission Electron Microscopy.- Figure 3 shows a HR-TEM image of two adjacent YSZ grains in the $3000 \mathrm{~h}$ aged sample. A low magnification image of the area where the grains are located can be seen in the inset. After the $3000 \mathrm{~h}$ aging, the monoclinic zirconia phase was formed adjacent to the main cubic zirconia phase. The crystal planes (1 3 - 1 ) and (2 00 ) of the monoclinic phase with a characteristic acute angle of $74.7^{\circ}$ can be observed for the bottom-right grain, while for the top-left grain the 
(1 11 1) crystal plane of the cubic phase is identified. The occurrence of the monoclinic phase is consistent with the aforementioned XRD results.

Cathode conductivity. - Figure 4 shows the evolution of the cathode conductivity measured at $900{ }^{\circ} \mathrm{C}$ in humidified air for four nominally identical cells. The average values of the four cells are also displayed. Conductivity values spread up to $20 \%$ between samples after $3000 \mathrm{~h}$, which is attributed to differences between samples inherent to the fabrication process.

The cathode conductivity values displayed in Figure 4 can be attributed to the electronic conduction in the LSM phase since LSM-YSZ composites shifts from an ionic conductor to an electronic conductor for LSM contents typically higher than 28 vol\% (solid phase fraction). ${ }^{40}$ The measured conductivity values are approximately two orders of magnitude lower than the bulk electronic conductivity value of similar LSM compositions (i.e. $\sim 200 \mathrm{~S} \mathrm{~cm}^{-1}$ ). ${ }^{41}$ These low conductivity values evidence the bottleneck effect $^{42}$ mainly caused by the narrow pathways which connect the LSM particles (see Figure 1). Nevertheless, the conductivity values increase over the entire period of $3000 \mathrm{~h}$ from approximately $1.1 \mathrm{~S} \mathrm{~cm}^{-1}$ to $2.5 \mathrm{~S} \mathrm{~cm}^{-1}$, with this increase being more pronounced in the first $1000 \mathrm{~h}$ (see Figure 4). Accordingly, we speculate that some activation effect occurs as the improvement with aging time in the LSM particle-to-particle contact.

Electrochemical Impedance Spectroscopy. - Impedance spectra recorded at both 650 and $850{ }^{\circ} \mathrm{C}$ in dry air corresponding to the reference and the $3000 \mathrm{~h}$ aged samples are displayed in Figure 5(a). All impedance spectra have been area (A) normalized and divided by two as to reflect the electrode response of one cathode. The spectra show a 
similar shape for the non-aged and for the aged samples, although the weight of the individual contributions depends on the aging time. Figure 5(b) displays the fitting of a typical impedance spectrum recorded at $650{ }^{\circ} \mathrm{C}$. The contributions tend to overlap at high temperature, increasing the error of the fitted parameters. Nevertheless, the residual plots (not shown) indicate very good fitting with a relative error below $1 \%$ for all spectra. The equivalent circuit used for fitting is shown in Figure 6. Element $L_{c}$ represents the inductance in the setup. The parallel subcircuit $\left(R_{E L} / / C P E_{E L}\right)$ composed of a resistance and a constant phase element (CPE) represents an additional arc, observed at the highest frequency only in the spectra recorded below $700{ }^{\circ} \mathrm{C}$. The rest of the equivalent circuit is composed of a parallel $R_{H F} / / C P E_{H F}$ subcircuit in series with the transmission line model described in the Appendix. An additional contribution can be clearly distinguished at very low frequencies, especially at low $p \mathrm{O}_{2}$ and high temperature (see Figure 7(a)). This additional contribution was fitted with a Warburg element, as can be seen in Figure 7(b). Similar results were obtained for the aged samples, although a considerable overlap of the two contributions at lower frequencies could be observed. In all cases, the relative error of the fitting was $1 \%$ or less.

Figure 8 shows the $R_{H F}$ and $R_{T L M}$ values as a function of the aging time, which were obtained by fitting spectra measured in dry air at 650 and $850{ }^{\circ} \mathrm{C}$. The total height of each column is equal to the cathode polarization resistance $R_{p o l}$ defined as the sum of $R_{H F}$ and $R_{T L M}$. Both contributions increase with aging time at $650{ }^{\circ} \mathrm{C}$ (see Figure 8(a)). The same is observed at $850{ }^{\circ} \mathrm{C}$ although the values recorded for the $300 \mathrm{~h}$ aged sample are lower than those of the reference sample. The proportion of each contribution relative to $R_{p o l}$ is also indicated in Figure 8 . The relative weight of $R_{H F}$ increases with aging time at $650{ }^{\circ} \mathrm{C}$, while it decreases for the $300 \mathrm{~h}$ aged sample and then increases for samples with longer 
aging time at $850{ }^{\circ} \mathrm{C}$. This indicates that the aging has stronger influence on $R_{H F}$. Nevertheless, this contribution only represents between 11 and $30 \%$ of $R_{\text {pol }}$ depending on the temperature and aging time.

In the following, the dependence of each contribution with temperature and oxygen partial pressure will be discussed, as to show which mechanisms limit the overall ORR in the composite LSM-YSZ cathode; while the variation with the aging time will give some insight on the degradation mechanisms.

Ohmic resistance contribution. - Figure 9 shows $R_{\text {ohm }}$ values for different aging times of the LSM-YSZ cathodes having been exposed to humidified air at $900{ }^{\circ} \mathrm{C} . R_{o h m}$ is defined as $R_{s}$ for high temperature spectra (see Figure 7(b)) and as the sum of $R_{S}$ and $R_{E L}$ for low temperature spectra (see Figure 5(b), $R_{E L}$ is attributed to the grain boundary resistance). The absolute value of $R_{o h m}$ and the activation energy values are within those expected for a 3YSZ electrolyte ${ }^{43}$ as shown in Figure 9(a). In addition, no dependence was observed with $\mathrm{pO}_{2}$ (not shown here). All this indicates that the $R_{\text {ohm }}$ can be safely attributed to the oxygen ion conduction through the electrolyte. $R_{\text {ohm }}$ values increase with aging time (see Figure 9(a)) with an activation energy (Ea) which remains within a narrow range of $0.85-0.92 \mathrm{eV}$. The aging tendency is similar regardless of the measuring temperature, although a higher relative increase can be noticed at lower temperatures (see Figure 9(b)). After 3000 h, a total increase of $40-45 \%$ is observed for all measuring temperatures. The increase of the grain boundary and the intragrain resistivity in 3YSZ electrolytes has been associated in the literature with the formation of several variants of the tetragonal phase along with monoclinic zirconia precipitates. ${ }^{43}$ 
High frequency contribution.- Figure 10 shows the resistance related to the high frequency contribution $\left(R_{H F}\right)$. A marked difference in the activation energy is observed between the reference sample $(0.84 \mathrm{eV})$ and the aged samples (1.10-1.17 eV range). As a consequence, the trend of the relative percentage variation depends on the measuring temperature (see Figure 10(b)). $R_{H F}$ values tend to stabilize for the $2500 \mathrm{~h}$ and $3000 \mathrm{~h}$ samples regardless of the measuring temperatures, although the final relative percentage degradation is higher as the measuring temperature lowers.

The $R_{H F}$ values are nearly independent on $p \mathrm{O}_{2}$ for the $0 \mathrm{~h}, 1500 \mathrm{~h}$ and $3000 \mathrm{~h}$ samples as can be seen in Figure 11(a). Equivalent capacitance values ${ }^{5}\left(C_{H F}\right)$ are within the $10^{-5.4}$ $-10^{-4.5} \mathrm{~F} / \mathrm{cm}^{2}$ range for the reference sample, and within the range $10^{-4.2}-10^{-4.5} \mathrm{~F} / \mathrm{cm}^{2}$ for the aged samples.

A high frequency arc has been frequently observed in the literature for the impedance spectra of LSM-YSZ composite cathodes and pure LSM cathodes on YSZ electrolytes. ${ }^{6-13,17,44-46}$ This high frequency contribution is typically characterized by: an activation energy in the range $0.77-1.05 \mathrm{eV}$, a slight $p \mathrm{O}_{2}$ dependency and an equivalent capacitance in the order of $10^{-4} \mathrm{~F} / \mathrm{cm}^{2}$. All these features are in agreement with what has been observed in the present study. Nevertheless, the origin of this high frequency arc has still not been resolved in the literature. In the case of LSM-YSZ cathodes, the resistance related to this contribution depends on the cathode thickness ${ }^{9,46}$, the YSZ content ${ }^{7,8}$, the microstructure of the cathode/electrolyte interface ${ }^{10}$, and the presence of $\mathrm{La}_{2} \mathrm{Zr}_{2} \mathrm{O}_{7}$ at the LSM/YSZ interfaces within the cathode ${ }^{17}$ and at the cathode/electrolyte interface. ${ }^{45,47}$ Juhl et al. ${ }^{46}$ have reported a change in the activation energy with temperature for the high frequency contribution in LSM-YSZ cathodes, indicating that more than one mechanism could be responsible for the high frequency response. Accordingly, Jørgensen and 
Mogensen ${ }^{6}$ have proposed that the high frequency contribution is related to two ORR limiting mechanisms which are difficult to separate: one is the transport of oxygen intermediates and/or oxide ions across the LSM/YSZ interfaces within the cathode, and the other is the transfer of oxygen ions to the YSZ electrolyte lattice. The presence of $\mathrm{La}_{2} \mathrm{Zr}_{2} \mathrm{O}_{7}$ at the LSM/YSZ interfaces within the cathode would affect the first mechanism, while the presence of reaction phases or impurities at the cathode/electrolyte interface would affect the second one. In the case of the samples studied in this work, the decomposition with aging time of $\mathrm{La}_{2} \mathrm{Zr}_{2} \mathrm{O}_{7}$ present in the cathode can explain the lower $R_{H F}$ values observed for the $300 \mathrm{~h}$ aged sample at higher temperatures (see Figure 10(b)). However, it cannot account for the higher $R_{H F}$ values found for samples with longer aging times, neither for the increasing $R_{H F}$ values with aging time observed for the $650{ }^{\circ} \mathrm{C}$ curve. In addition, the activation energy and the capacitances are different for the reference and the aged samples (see Figure 10(a)). All these facts suggest that the high frequency contribution can be a combination of two limiting steps as proposed by Jørgensen and Mogensen. ${ }^{6}$ In view of that, we speculate that the presence of $\mathrm{La}_{2} \mathrm{Zr}_{2} \mathrm{O}_{7}$ at the LSM/YSZ interfaces within the cathode plays a predominant role in the reference sample while the oxygen ion transfer at the cathode/electrolyte interface would dominate in the aged samples. In that case, the increase in $R_{H F}$ for aging times longer than $300 \mathrm{~h}$ would imply some degradation phenomenon as the presence of poor ionic conducting phases such as monoclinic zirconia phase at cathode/electrolyte interface.

Effective ionic conductivity. - The effective ionic conductivity values of the 8YSZ network inside the cathode are displayed in Figure 12 (shown as $\sigma_{\text {YSZ }}^{\text {eff }}$ ). These values were calculated according to equation A5. The activation energy of $\sigma^{\text {eff }}{ }_{\text {YSZ }} T$ for the aged 
cathodes is within the 1.34-1.46 eV range and it is noticeably higher than the Ea of 1.00 eV corresponding to the reference sample (see Figure 12(a)). The activation energy of the reference sample is within the expected values for $8 \mathrm{YSZ}^{43}$, while these values are significantly higher for the aged samples. Figure 12(b) shows that the effective ionic conductivity is lower for samples with increasing aging time for all the measuring temperatures, although it tends to stabilize for samples with aging longer than $1500 \mathrm{~h}$. In addition, the effective ionic conductivity is relatively lower for the aged samples at the lower temperatures. Several authors have also observed a decrease in conductivity and an increase in the activation energy of yttria, scandia and holmia doped zirconia electrolytes after aging within the $800-1000{ }^{\circ} \mathrm{C}$ range. ${ }^{29,48-50}$ Kondoh et al. has attributed this behavior to a short-range ordering and trapping of oxygen ion vacancies, which requires higher activation energy for conduction after aging. ${ }^{48}$ The short-range ordering of oxygen ion vacancies was associated by Kondoh et al. to a shrinkage of the "hump on the left shoulder” in the X-ray diffractograms. ${ }^{28}$ Our X-ray data also displays a decrease in the intensity of this feature for the aged samples, along with the formation of a small quantity of monoclinic zirconia for aging times longer than 2500 h (see Figure 2). The presence of $\mathrm{m}-\mathrm{ZrO}_{2}$ is detrimental for the conductivity of the YSZ network within the cathode not only because its ionic conductivity is several orders of magnitude lower than that of cubic $\mathrm{YSZ}^{51}$ but also because the presence of $\mathrm{m}-\mathrm{ZrO}_{2}$ grains in the $\mathrm{YSZ}$ network would produce a loss of percolation. Therefore, the decrease in ionic conductivity observed for the YSZ network inside the cathode is likely to be caused by the same degradation phenomena observed by Kondoh et al. $^{28,48}$ and, to a lesser extent, the formation of m$\mathrm{ZrO}_{2}$. 
The effective ionic conductivity values determined from the reference sample slightly depend on $p \mathrm{O}_{2}$ regardless of the measuring temperature (see Figure 13), as expected for 8YSZ. ${ }^{43}$ The same was observed for the 1500 and $3000 \mathrm{~h}$ aged samples at $850{ }^{\circ} \mathrm{C}$. Nevertheless, the ionic conductivity of the aged samples at 650 and $750{ }^{\circ} \mathrm{C}$ increases as $\left(\mathrm{pO}_{2}\right)^{0.3 \pm 0.05}$. This effect could be related to the short-ordering of oxygen ion vacancies observed in the aged samples or with another mechanism as, for example, $\mathrm{O}^{-}$surface diffusion. In this regard, Kim et al. ${ }^{7}$ have derived a $\left(\mathrm{pO}_{2}\right)^{0.25}$ dependency for the inverse of the resistance which is in good agreement with that observed in this work for the aged samples at low temperatures.

Charge transfer contribution.- The resistance values $\left(r_{\mathrm{ct}}\right)$ related to the charge transfer between LSM and YSZ are plotted in Figure 14. These values were normalized by the triple phase boundary length $\left(l_{T P B}\right)$ determined by SEM, as follows $r_{c t}^{T P B}=r_{c t} l_{T P B} A$. Aged samples exhibit lower $r_{c t}^{T P B}$ values than the reference with the exception of the $2500 \mathrm{~h}$ sample measured at 650 and at $850{ }^{\circ} \mathrm{C}$, although no clear tendency with respect to the aging time could be established (see Figure 14(a)). The activation energy values are within the 1.52-1.66 eV range. The slope of the $\log r_{c t}{ }^{\text {TPB }}$ plot is between -0.21 and -0.39 , and it does not appear to be influenced by the measuring temperature (see Figure 14(b)). $r_{c t}^{T P B}$ values present similar activation energy values and $p \mathrm{O}_{2}$ dependency for the reference and the aged samples. These are within the reported for charge transfer occurring during the oxygen reduction reaction at the triple phase boundary (TPB). ${ }^{6,11,17}$

Figure 15 shows the characteristic length $(\lambda)$ values which represent the relationship between the ionic conductivity of the cathode and the rate of charge transfer between LSM and YSZ (see equation A6). This parameter is larger for the reference sample, while 
all the aged samples present similar values within the errors bars. $\lambda$ values decrease with increasing temperatures for all samples. Since no significant change has been observed for the $r_{c t}^{T P B}$ values, the lower $\lambda$ values observed in Figure 15 for the aged samples are mostly related to the poorer ionic conductivity of the aged cathodes causing the electrode reaction to contract towards the electrolyte interface. ${ }^{52}$ The electrochemically active thickness of the cathode is the region adjacent to the cathode/electrolyte interface were most of the electronic/ionic current exchange (i.e. the oxygen reduction reaction) occurs and can be estimated as 3 times the characteristic length (see the Appendix). Therefore, the electrochemically active thickness decreases from 60-135 $\mu \mathrm{m}$ to $45-60 \mu \mathrm{m}$ (depending on temperature) after $3000 \mathrm{~h}$ aging.

Figure 16 shows the dependency of $\lambda$ with $\mathrm{pO}_{2}$. Once again the behavior observed for the reference samples differs from the one observed for the aged samples. $\lambda$ values at $650{ }^{\circ} \mathrm{C}$ strongly increase with decreasing $\mathrm{pO}_{2}$ for the reference sample, although the dependence becomes weaker as the measuring temperature increases. In the case of the aged samples, only a slight dependence on $\mathrm{pO}_{2}$ is observed at $850{ }^{\circ} \mathrm{C}$ while no clear dependence with $\mathrm{pO}_{2}$ or aging time is observed at lower temperatures. The oxygen supply is depleted as the $\mathrm{pO}_{2}$ decreases producing a slower charge transfer reaction rate and hence more reaction sites located far from the cathode/electrolyte interface become active, giving rise to a larger value of $\lambda$ in the case of the reference sample. This effect is more evident at lower temperatures where the reaction rate is slower. In the case of the aged samples, the charge transfer resistance and the oxygen ion conduction present opposite dependency with $\mathrm{pO}_{2}$ (compare Figures 13 and 14(b)) and hence $\lambda$ is almost independent on $\mathrm{pO}_{2}$ (see equation $\mathrm{A6}$ ). 
Additional low frequency contribution.- As mentioned before, an additional contribution could be clearly distinguished at very low frequencies in the impedance spectra recorded at high temperature and low $p \mathrm{O}_{2}$. The $\mathrm{pO}_{2}$ dependency of the resistance $R_{w}$ related to this contribution is shown in Figure 17. $R_{w}$ values are inversely proportional to $\mathrm{pO}_{2}$, and they are similar regardless the aging time. In addition, the summit frequency of this contribution is within the $2-9 \mathrm{~Hz}$ range (see Figure 7(a)). All this indicate that this extra contribution can be interpreted as oxygen gas diffusion in the stagnant gas layer located at the top of the cathode. ${ }^{6}$

\section{Conclusions}

A transmission line based model was successfully applied to study the aging effect on LSM-YSZ cathodes after being exposed to humidified air at $900{ }^{\circ} \mathrm{C}$ for up to $3000 \mathrm{~h}$. This model allowed obtaining relevant parameters related to the transport and the electrochemical properties of the cathodes. The ionic conductivity values of the reference non-aged sample are within the expected ones for YSZ with an activation energy of 1.0 $\mathrm{eV}$ and nearly no dependency on $\mathrm{pO}_{2}$, while the LSM/YSZ charge transfer resistance presents an activation energy of $1.6 \mathrm{eV}$ and is proportional to $\left(\mathrm{pO}_{2}\right)^{-0.31 \pm 0.08}$. The used model is validated by the good agreement between these parameters and those previously reported in the literature. Furthermore, the changes observed in the transport and electrochemical properties of the cathodes upon aging are mostly related to the evolution of the present phases detected by XRD and TEM. The formation of monoclinic zirconia along with the relaxation of YSZ lattice distortions (reflected by the disappearance of the 
HLS feature on XRD diffractograms) have a degradation effect, decreasing the ionic conductivity up to $79 \%$, diminishing the electrochemically active thickness from 60-135 $\mu \mathrm{m}$ to $45-60 \mu \mathrm{m}$, and contracting the reaction zone towards the cathode/electrolyte interface. The diminution of the $\mathrm{La}_{2} \mathrm{Zr}_{2} \mathrm{O}_{7}$ amount in the initial stage of aging has an activation effect on the cathode polarization resistance by reducing the high frequency contribution up to $\sim 39 \%$. Nevertheless, the high frequency contribution increases with longer aging times up to $\sim 172 \%$ because of the diminution of cathode ionic conductivity which hinders the oxygen ion transfer through the cathode/electrolyte interface. Based on all the above, the performed analysis using the transmission line model has been proven to be effective for identifying the activation and degradation mechanisms which affect the transport and the electrochemical properties of the cathode and its performance.

\section{Acknowledgments}

The research leading to these results has received funding from the European Union's Seventh Framework Program (FP7/2007-2013) for the Fuel Cells and Hydrogen Joint Technology Initiative under grant agreement $n^{\circ}$ 526885. This work was also financed by Energinet.dk through the project ForskEL 2011-1-10625 “SOFC-Life” with DKK 3.618 million. N. Bonanos is acknowledged for assistance in impedance measurements and useful discussion, and P. H. Nielsen is acknowledged for SEM sample preparation. 


\section{Appendix}

Figure A1 shows a simplified sketch depicting a porous LSM-YSZ cathode. The transmission line model takes into account the oxide ion conduction through the YSZ phase (represented by impedance $\chi_{1}$ ), the electronic conduction through the LSM phase (represented by impedance $\chi_{2}$ ), and the charge transfer between LSM and YSZ (represented by impedance $\zeta$ ). The latter can occur as transfer of oxygen intermediates between LSM and YSZ or as transformation from electronic to ionic current during the oxygen reduction reaction at the TPB. ${ }^{6}$ The impedance of the transmission line is defined by the following expression: ${ }^{14,15}$

$$
Z_{T L M}=\frac{\chi_{1} \chi_{2}}{\chi_{1}+\chi_{2}}\left(L+\frac{2 \lambda}{\sinh (L / \lambda)}\right)+\lambda \frac{\chi_{1}^{2}+\chi_{2}^{2}}{\chi_{1}+\chi_{2}} \operatorname{coth}(L / \lambda)
$$

where $L$ is the cathode thickness and $\lambda$ is defined by:

$$
\lambda=\sqrt{\frac{\zeta}{\chi_{1}+\chi_{2}}}
$$

The impedance $\zeta$ is composed of a distributed resistance $\left(r_{c t}\right)$ in parallel with a distributed CPE, yielding the expression: ${ }^{15}$

$$
\zeta=\frac{r_{c t}}{1+r_{c t} q_{c t}(j \omega)^{\beta_{c t}}}
$$


where $r_{c t}$ is a distributed resistance related to the charge transfer between LSM and YSZ, and $q_{c t}$ and $\beta_{c t}$ are the adjustable parameters of the CPE element. ${ }^{27}$

In the case of the LSM-YSZ electrode, the impedance $\chi_{1}$ is a distributed resistance $\left(r_{1}\right)$ representing the resistivity of YSZ. Additionally, the impedance $\chi_{2}$ can be neglected since the LSM electronic conductivity is significantly higher than the YSZ conductivity. Thus, the impedance expression in equation A1 can be simplified to: ${ }^{14,15}$

$$
Z_{\text {TLM }}=\lambda \chi_{1} \operatorname{coth}(L / \lambda)
$$

The ZView distributed element DX- $11^{27}$ was used to implement the transmission line model in the equivalent circuit. Parameters $r_{1}, r_{c t}, q_{c t}$ and $\beta_{c t}$ were allowed to vary freely while the cathode thickness $L$ was fixed to $50 \mu \mathrm{m}$.

The effective ionic conductivity values within the YSZ network can be estimated from the distributed resistance $r_{1}$ and the cathode area $A$ according to the formula: ${ }^{14}$

$$
\sigma_{Y S Z}^{\text {eff }}=\frac{1}{r_{1} A}
$$

The characteristic length $\lambda$ can be calculated as: ${ }^{52}$

$$
\lambda=\sqrt{\frac{r_{c t}}{r_{1}}}=\sqrt{r_{c t} \sigma_{Y S Z}^{e f f} A}
$$

Accordingly, $\lambda$ represents the relationship between the ionic conductivity of the cathode and the rate of charge transfer between LSM and YSZ. In order to illustrate the 
significance of this parameter, assume a cathode thickness $L=3 \lambda$. By replacing in equation $\mathrm{A} 4$, it is clear that the transmission line impedance is 1.005 times the impedance of a cathode with infinite thickness. For a cathode with thickness $L=3 \lambda$, the exchange from electronic current into ionic is equal to $99.5 \%$ of the current exchange occurring in an electrode with infinite thickness. Therefore, the increase of cathode thickness beyond $3 \lambda$ does not augment the number of active sites for the ORR. In this way, the electrochemically active thickness of the cathode can be estimated as 3 times the characteristic length $\lambda$ and it represents the region adjacent to the cathode/electrolyte interface where most of the electronic/ionic current exchange has occurred.

\section{References}

1. R. Knibbe, A. Hauch, J. Hjelm, S. D. Ebbesen and M. Mogensen, Green, 1, 141 (2011).

2. H. Yokokawa, H. Tu, B. Iwanschitz and A. Mai, J. Power Sources, 182, 400 (2008).

3. Y. L. Liu, K. Thydén, M. Chen and A. Hagen, Solid State Ionics, 206, 97 (2012).

4. M. J. Jørgensen, P. Holtappels and C. C. Appel, J. Applied Electrochemistry, 30, 411 (2000).

5. J. Nielsen and M. Mogensen, Solid State Ionics, 189, 74 (2011).

6. M. J. Jørgensen and M. Mogensen, J. Electrochem. Soc., 148, A433 (2001).

7. J.-D. Kim, G.-D. Kim, J.-W. Moon, Y. Park, W.-H. Lee, K. Kobayashi, M. Nagai and C.-E. Kim, Solid State Ionics, 143, 379 (2001). 
8. S. Wang, Y. Jiang, Y. Zhang, J. Yan and W. Li, Solid State Ionics, 113-115, 291 (1998).

9. E. P. Murray, T. Tsai and S. A. Barnett, Solid State Ionics, 110, 235 (1998).

10. Y. J. Leng, S. H. Chan, K. A. Khor and S. P. Jiang, J. Applied Electrochemistry, 34, 409 (2004).

11. E. C. Thomsen, G. W. Coffey, L. R. Pederson and O. A. Marina, J. Power Sources, 191, 217 (2009).

12. S. R. Gamble and J. T. S. Irvine, Solid State Ionics, 192, 394 (2011).

13. S. Bebelis, N. Kotsionopoulos, A. Mai, D. Rutenbeck and F. Tietz, Solid State Ionics, 177, 1843 (2006).

14. J. Bisquert, G. Garcia-Belmonte, F. Fabregat-Santiago and A. Compte, Electrochem. Comm., 1, 429 (1999).

15. J. Bisquert, Phys. Chem. Chem. Phys., 2, 4185 (2000).

16. V. Sonn, A. Leonide and E. Ivers-Tiffée, J. Electrochem. Soc., 155, B675 (2008).

17. J. Nielsen and J. Hjelm, Electrochimica Acta, 115, 31 (2014).

18. A. Hahn, and H. Landes, in Proceedings of the Fifth International Symposium om Solid Oxide Fuel Cells (SOFC-V), U. Stimming, S. C. Singhal, H. Tagawa, W. Lehnert, Editors, p. 595, The Electrochemical Society, Pennington, NJ (1997).

19. J. Fleig, Annu. Rev. Mater. Res., 33, 361 (2003).

20. V. Sonn, A. Leonide, and E. Ivers-Tiffée, ECS Trans., 7, 1363 (2007).

21. A. Utz, J. Joos, A. Weber, and E. Ivers-Tiffée, ECS Trans., 35, 1669 (2011).

22. A. Leonide, Y. Apel, and E. Ivers-Tiffée, ECS Trans., 19, 81 (2009).

23. S. Gewies, and W. G.. Bessler, J. Electrochem. Soc., 155, B937 (2008). 
24. L. C. Baqué, P. S. Jørgensen, K. V. Hansen, and M. Søgaard, ECS Trans., 57, 2027 (2013).

25. W. Zhang, L. Theil Kuhn, P. Jørgensen, K. Thydén, J. Bentzen, E. Abdellahi, B. R. Sudireddy, M. Chen and J. R. Bowen, Microscopy and Microanalysis, 19, 501 (2013).

26. L. J. van der Pauw, Philips Technical Review, 20, 220 (1958/59).

27. Scribner Associates, ZView for Windows, Version 3.2c, 2010.

28. J. Kondoh, S. Kikuchi, Y. Tomii, and Y. Ito, J. Electrochem.Soc., 145, 1536 (1998).

29. J. Kondoh, Y. Tomii, and K. Kawachi, J. Am. Ceram. Soc., 86, 2093 (2003).

30. L. Ruiz, and M. Readey, J. Am. Ceram. Soc., 79, 2331 (1996).

31. Y. Kitano, Y. Mori, and A. Ishitani, J. Am. Ceram. Soc., 71, C-34 (1988).

32. H. Hasegawa, J. Mater. Sci. Lett., 2, 91 (1983).

33. H. Hasegawa, T. Hioki, and O. Kamigaito, J. Mater. Sci. Lett., 4, 1092 (1985).

34. D. P. Burke, and W. M. Rainforth, J. Mater. Sci. Lett., 16, 883 (1997).

35. M. A. Idris, S. Li, and J. Nowotny, J. JSEM, 11, SS256 (2011).

36. M. R. Terner, J. A. Schuler, A. Mai, and D. Penner, Solid State Ionics, 263, 180 (2014).

37. M. Chen, Y.-L. Liu, A. Hagen, P. V. Hendriksen and F. W. Poulsen, Fuel Cells, 9, 833 (2009).

38. A. Mitterdorfer and L. J. Gauckler, Solid State Ionics, 111, 185 (1998).

39. A. Weber, R. Männer, B. Jobst, M. Schiele, H. Cerva, R. Waser, and E. IversTiffée, in High Temperature Electrochemistry: Ceramics and Metals, F. W. Poulsen, 
N. Bonanos, S. Linderoth, M. Mogensen, B. Zachau Christiansen, Editors, p. 473, Risø National Laboratory, Denmark (1996).

40. Y. Ji, J. A. Kilner, M. F. Carolan, Solid State Ionics, 176, 937 (2005).

41. J. Mizusaki, Y. Yonemura, H. Kamata, K. Ohyama, N. Mori, H. Takai, H. Tagawa, M. Dokiya, K. Naraya, T. Sasamoto, H. Inaba and T. Hashimoto, Solid State Ionics, 132, 167 (2000).

42. L. Holzer, D. Wiedenmann, B. Münch, L. Keller, M. Prestat, Ph. Gasser, I. Robertson and B. Grobéty, J. Mater. Sci., 48, 2934 (2013).

43. F. T. Ciacchi, K. M. Crane, and S. P. S. Badwal, Solid State Ionics, 73, 49 (1994).

44. S. P. Jiang, J. G. Love, and Y. Ramprakash, J. Power Sources, 110, 201 (2002).

45. H. Y. Lee and S. M. Oh, Solid State Ionics, 90, 133 (1996).

46. M. Juhl, S. Primdahl, and M. Mogensen, in High Temperature Electrochemistry: Ceramics and Metals, F. W. Poulsen, N. Bonanos, S. Linderoth, M. Mogensen, and B. Zachau-Christiansen, Editors, p. 295, Risø National Laboratory, Denmark (1996).

47. G. Chiodelli and M. Scagliotti, Solid State Ionics, 73, 265 (1994).

48. J. Kondoh, T. Kawashima, S. Kikuchi, Y. Tomii, and Y. Ito, J. Electrochem. Soc., 145, 1527 (1998).

49. F. T. Ciacchi, and S. P. S: Badwal, J. Europ. Ceram. Soc., 7, 197 (1991).

50. A. N. Vlasov, and M. V. Perfiliev, Solid State Ionics, 25, 245 (1987).

51. M. M. Nasrallah and D. L. Douglass, J. Electrochem. Soc., 121, 255 (1974).

52. M. Kishimoto, H. Iwai, M. Saito, and H. Yoshida, ECS Trans., 57, 2515 (2013). 
Table I. Microstructure parameters as a function of aging time.

\begin{tabular}{|c|c|c|c|c|c|c|c|c|}
\hline Aging time (h) & 0 & 300 & 1000 & 1500 & 2500 & 3000 & Mean $^{a}$ & Std. ${ }^{a}$ \\
\hline LSM phase fraction & 0.19 & 0.18 & 0.19 & 0.19 & 0.19 & 0.21 & 0.19 & 0.009 \\
\hline Pore phase fraction & 0.42 & 0.44 & 0.44 & 0.43 & 0.44 & 0.43 & 0.44 & 0.004 \\
\hline YSZ phase fraction & 0.39 & 0.38 & 0.37 & 0.37 & 0.38 & 0.36 & 0.37 & 0.006 \\
\hline LSM/Pore interface area $\left(\mu \mathrm{m}^{-1}\right)$ & 0.93 & 0.83 & 0.93 & 0.99 & 0.89 & 0.92 & 0.91 & 0.06 \\
\hline LSM/YSZ interface area $\left(\mu \mathrm{m}^{-1}\right)$ & 1.43 & 1.30 & 1.38 & 1.40 & 1.33 & 1.48 & 1.38 & 0.07 \\
\hline Pore/YSZ interface area $\left(\mu \mathrm{m}^{-1}\right)$ & 4.36 & 3.95 & 3.70 & 3.71 & 3.79 & 3.40 & 3.7 & 0.2 \\
\hline LSM interface area $\left(\mu \mathrm{m}^{-1}\right)$ & 2.36 & 2.13 & 2.31 & 2.39 & 2.23 & 2.39 & 2.3 & 0.1 \\
\hline Pore interface area $\left(\mu \mathrm{m}^{-1}\right)$ & 5.29 & 4.78 & 4.63 & 4.70 & 4.69 & 4.32 & 4.6 & 0.2 \\
\hline YSZ interface area $\left(\mu \mathrm{m}^{-1}\right)$ & 5.79 & 5.25 & 5.08 & 5.11 & 5.13 & 4.88 & 5.2 & 0.1 \\
\hline$l_{T P B}\left(\mu \mathrm{m}^{-2}\right)$ & 13.7 & 11.6 & 12.6 & 13.2 & 12.5 & 12.3 & 12.4 & 0.6 \\
\hline LSM particle radius $^{\mathrm{b}}(\mathrm{nm})$ & 162 & 177 & 167 & 171 & 174 & 177 & 173 & 4.3 \\
\hline Pore particle radius ${ }^{\mathrm{b}}(\mathrm{nm})$ & 149 & 172 & 180 & 176 & 178 & 191 & 179 & 7.4 \\
\hline YSZ particle radius ${ }^{\mathrm{b}}$ (nm) & 115 & 128 & 132 & 131 & 131 & 134 & 131 & 2.3 \\
\hline \multicolumn{9}{|c|}{${ }^{\mathrm{a}}$ The mean and standard deviation columns have been calculated using data from al } \\
\hline \multicolumn{9}{|c|}{${ }^{\mathrm{b}}$ Particle radius refers to the $50^{\text {th }}$ percentile values extracted from the $2 \mathrm{D}$ continuous } \\
\hline
\end{tabular}


(a) $0 \mathrm{~h}$

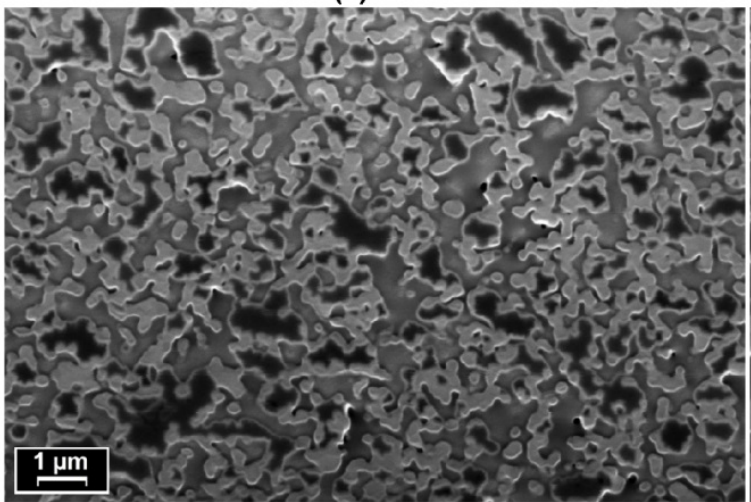

(b) $3000 \mathrm{~h}$

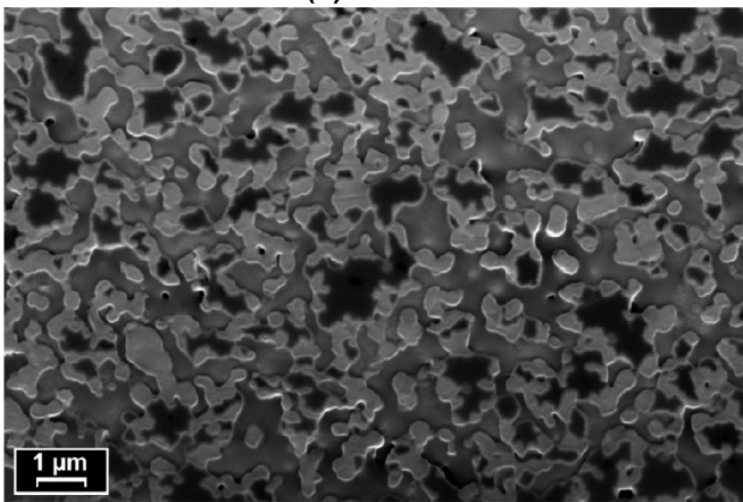

Figure 1. SEM image showing the cathode microstructure of (a) the reference sample and (b) the $3000 \mathrm{~h}$ aged sample. The images were acquired by focused ion beam imaging using the InLens detector. The dark regions of the image correspond to the LSM phase, the bright regions to the YSZ phase, and the intermediate intensity regions correspond to epoxy filled pores.

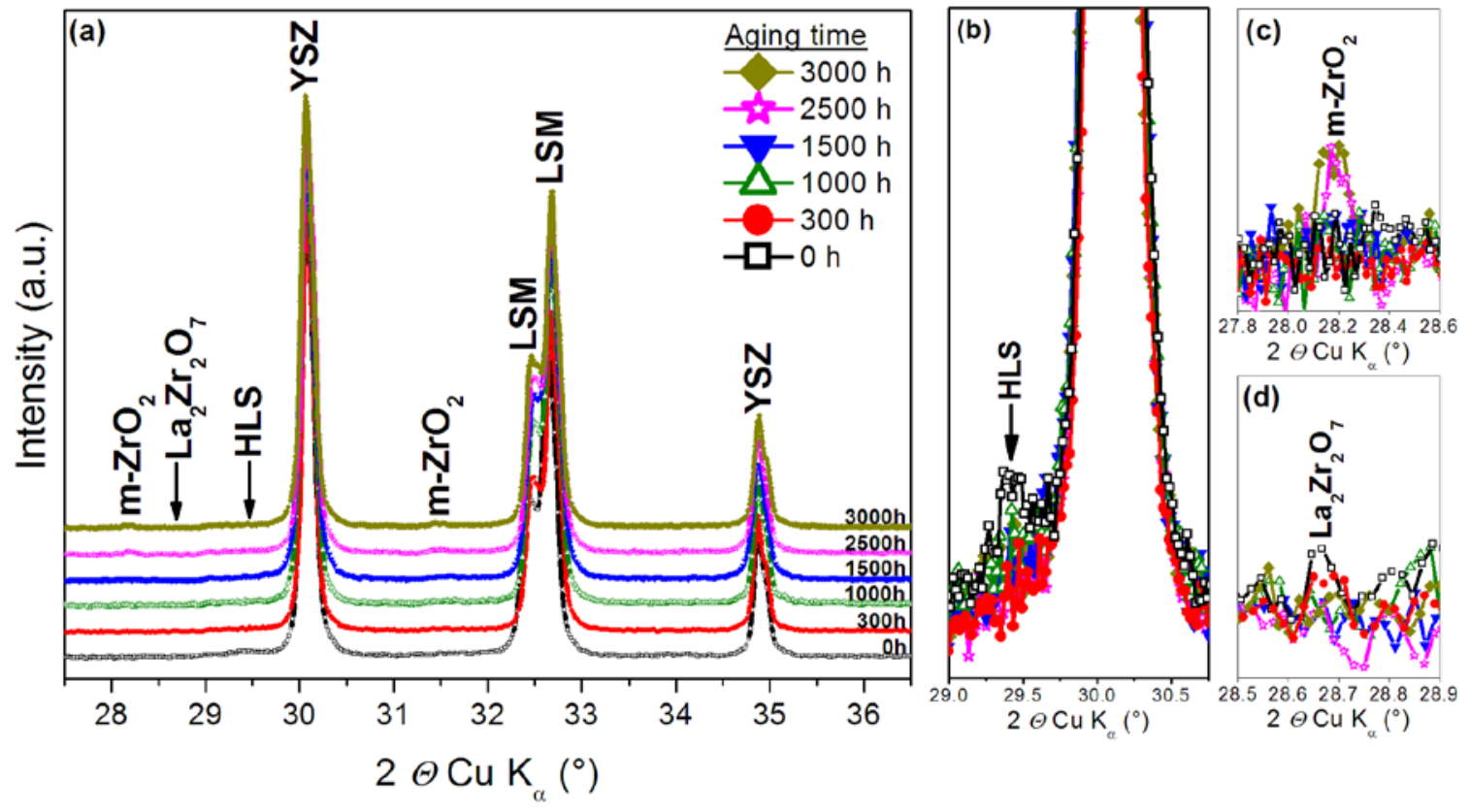

Figure 2. (Color online) (a) Overview and (b,c,d) detail of XRD diffraction patterns collected at room temperature for LSM-YSZ cathodes after being aged at $900{ }^{\circ} \mathrm{C}$ in humidified air. HLS: Hump on the left shoulder (see text). 


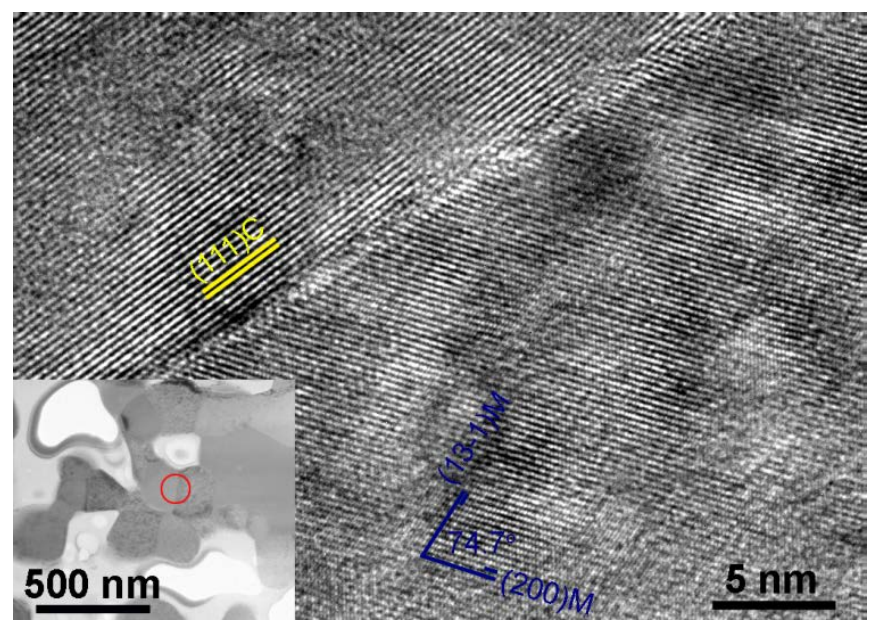

Figure 3. (Color online) HR-TEM image of the circled area (of the inset, lowmagnification TEM image) in the $3000 \mathrm{~h}$ aged sample.

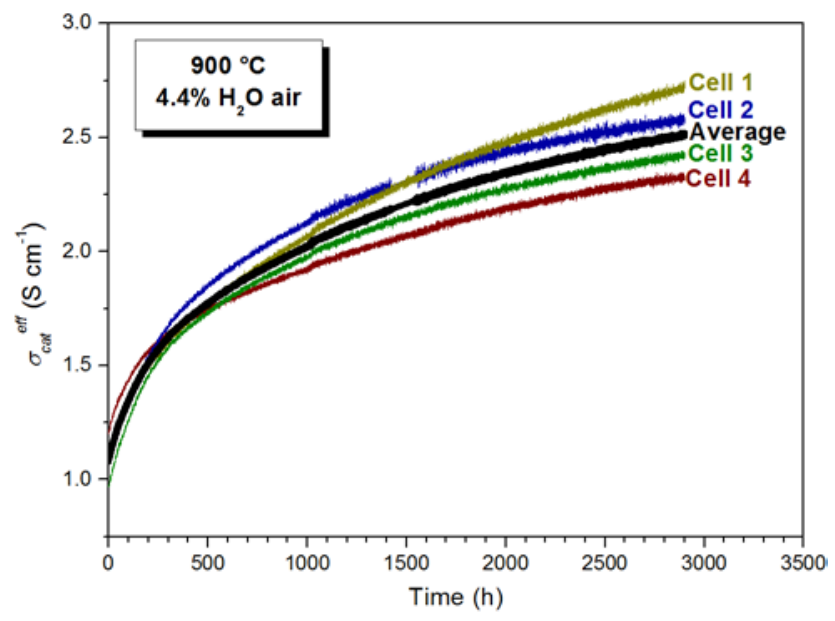

Figure 4. (Color online) Conductivity data of four nominally identical LSM-YSZ cathodes measured at $900{ }^{\circ} \mathrm{C}$ in air containing $4.4 \% \mathrm{H}_{2} \mathrm{O}$. The average values of the four cathodes are also shown. 
(a)
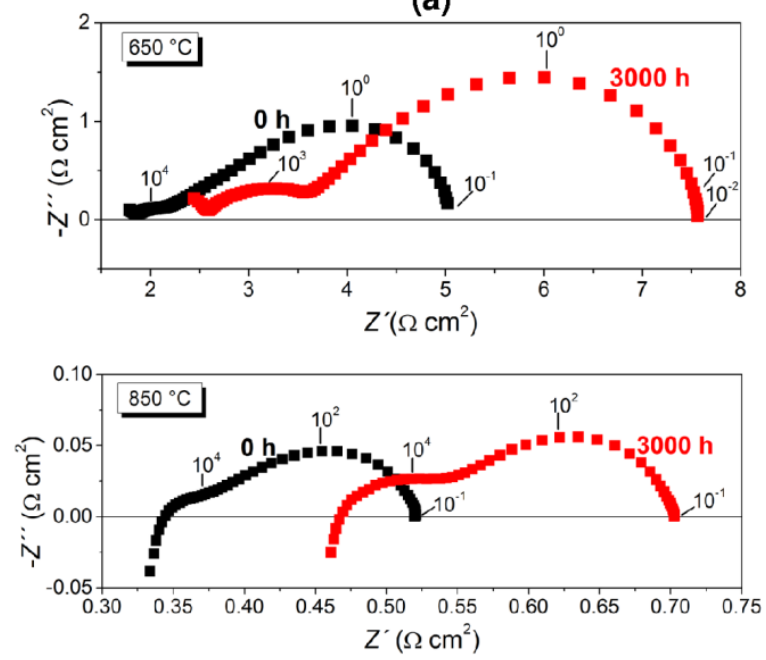

(b)
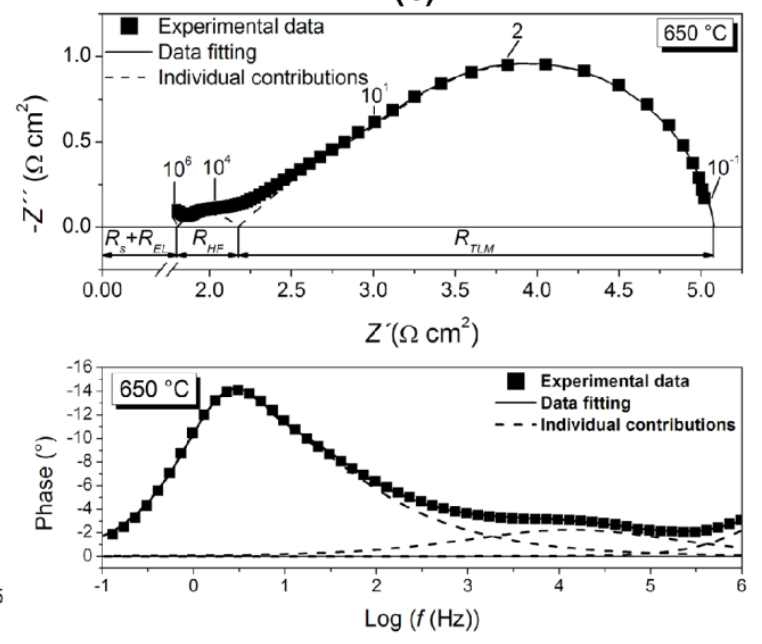

Figure 5. (Color online) (a) Nyquist plot of impedance spectra for the reference and the $3000 \mathrm{~h}$ aged samples recorded in dry air at $650{ }^{\circ} \mathrm{C}$ (top) and $850{ }^{\circ} \mathrm{C}$ (bottom). The numbers indicate the frequency in Hertz. (b) Nyquist and Bode plots showing the fitting of the impedance spectra recorded at $650{ }^{\circ} \mathrm{C}$ for the reference sample $(0 \mathrm{~h})$.

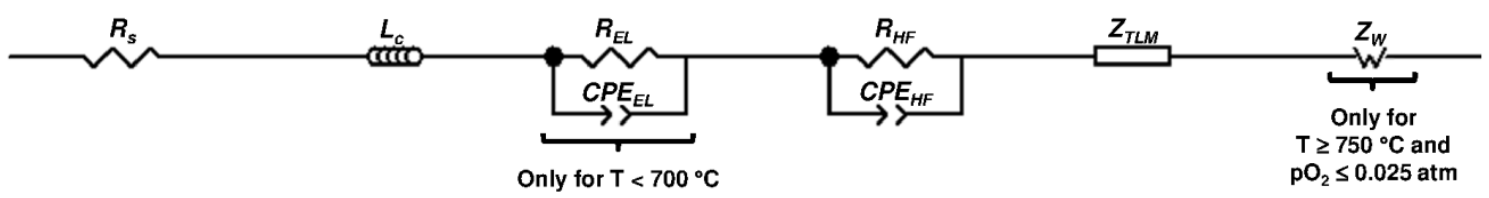

Figure 6. Equivalent circuit used to fit the spectra. 
(a)
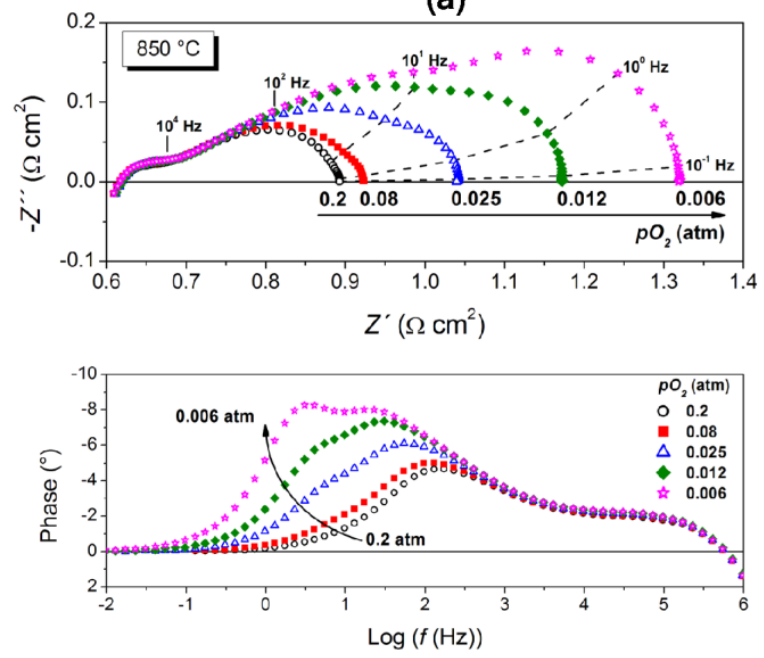

(b)
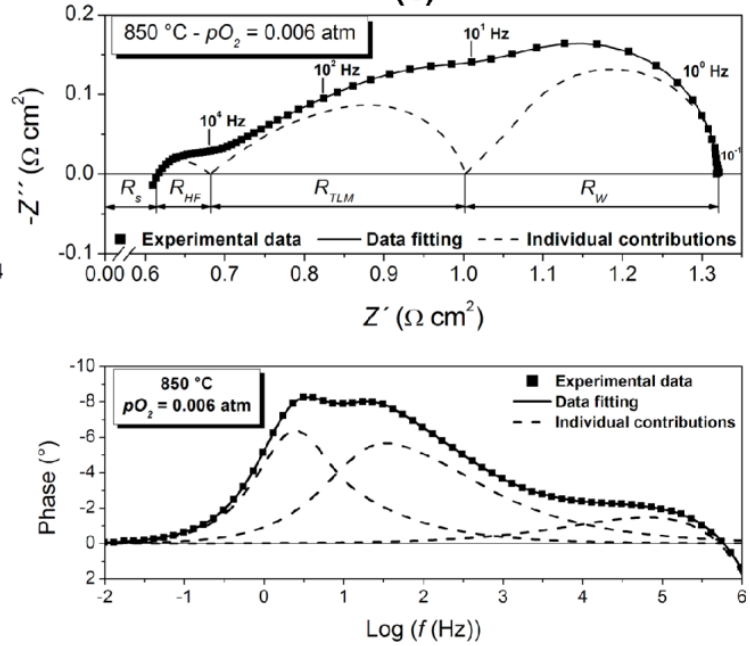

Figure 7. (Color online) (a) Nyquist and Bode plots of impedance spectra for the reference sample $(0 \mathrm{~h})$ recorded at $850{ }^{\circ} \mathrm{C}$ under different oxygen partial pressures. (b) Fitting of the impedance spectra recorded under $\mathrm{pO}_{2}=0.006 \mathrm{~atm}$. 

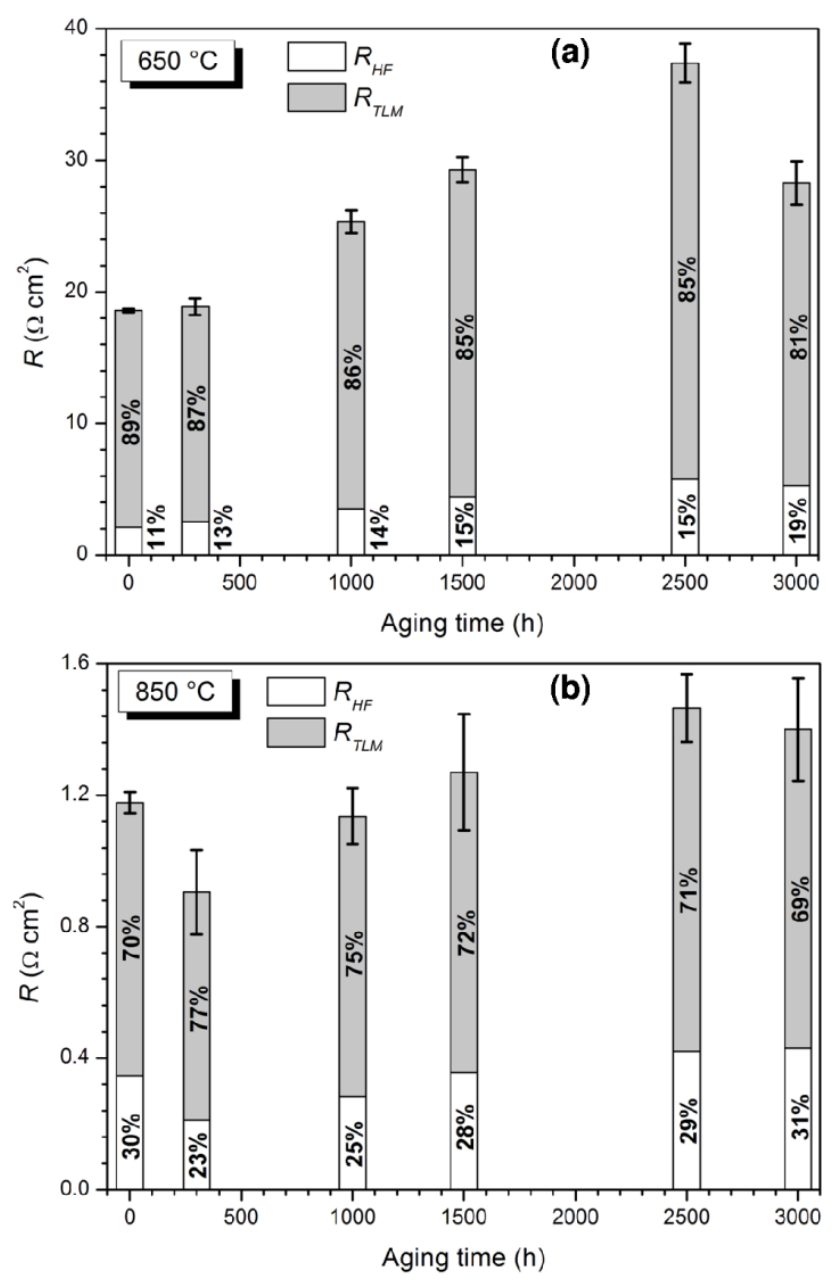

Figure 8. $R_{H F}$ and $R_{T L M}$ values measured at (a) 650 and (b) $850{ }^{\circ} \mathrm{C}$ as a function of the aging time. The error bars correspond to the error in determining $R_{p o l}=R_{H F}+R_{T L M}$. The numbers in the columns indicate the proportion of each contribution relative to $R_{p o l}$. 

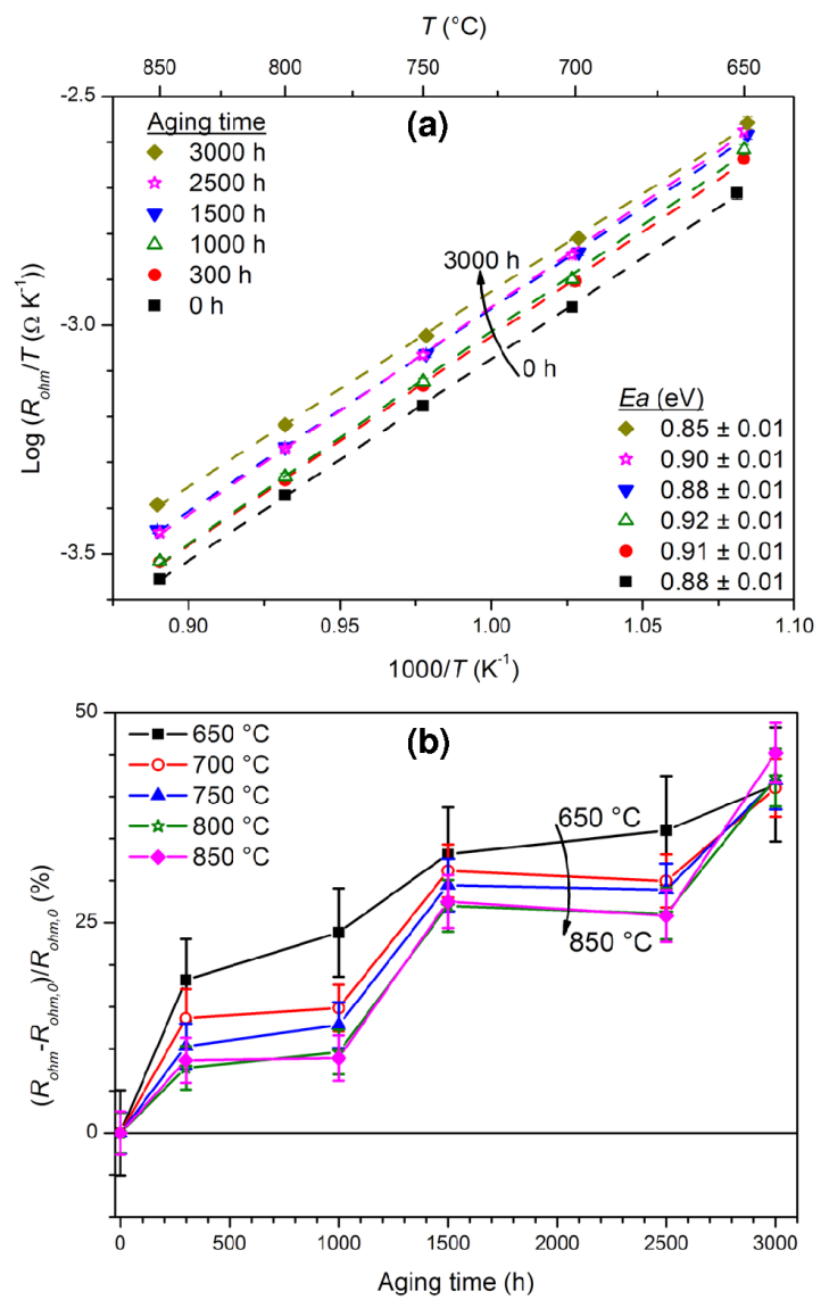

Figure 9. (Color online) (a) Arrhenius plot and (b) relative percentage variation of $R_{o h m}$ values for LSM-YSZ cathodes after being aged at $900{ }^{\circ} \mathrm{C}$ in humidified air. The arrows represent the direction of increasing aging time in (a) and of increasing temperature in (b). 

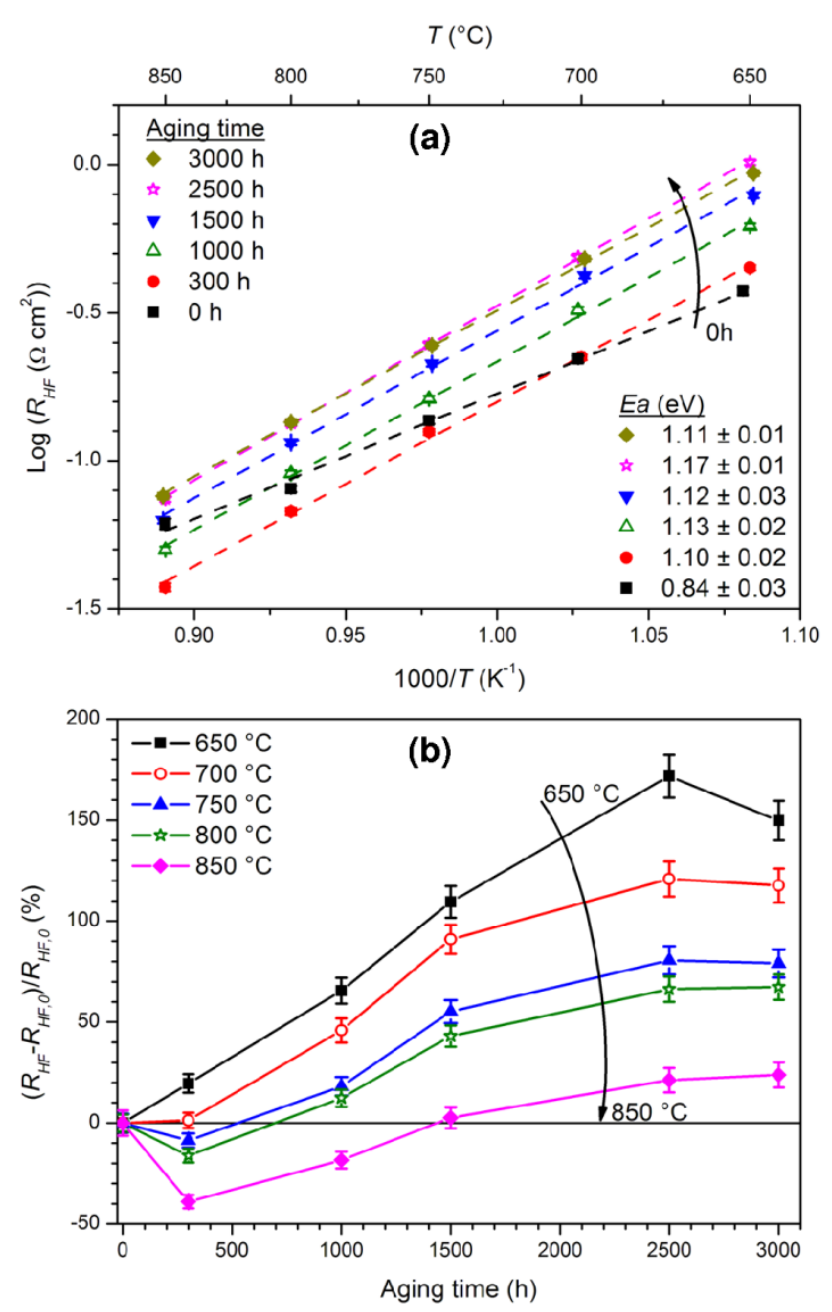

Figure 10. (Color online) (a) Arrhenius plot and (b) relative percentage variation of $R_{H F}$ values for LSM-YSZ cathodes after being aged at $900{ }^{\circ} \mathrm{C}$ in humidified air. The arrows represent the direction of increasing aging time in (a) and of increasing temperature in (b). 


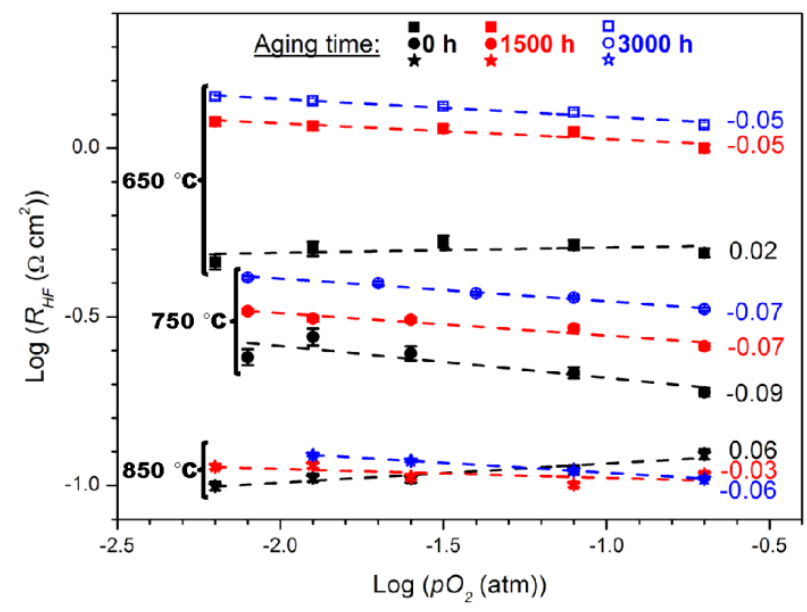

Figure 11. (Color online) Dependence of $R_{H F}$ on $p \mathrm{O}_{2}$ at different temperatures for LSMYSZ cathodes after being aged at $900{ }^{\circ} \mathrm{C}$ in humidified air. 

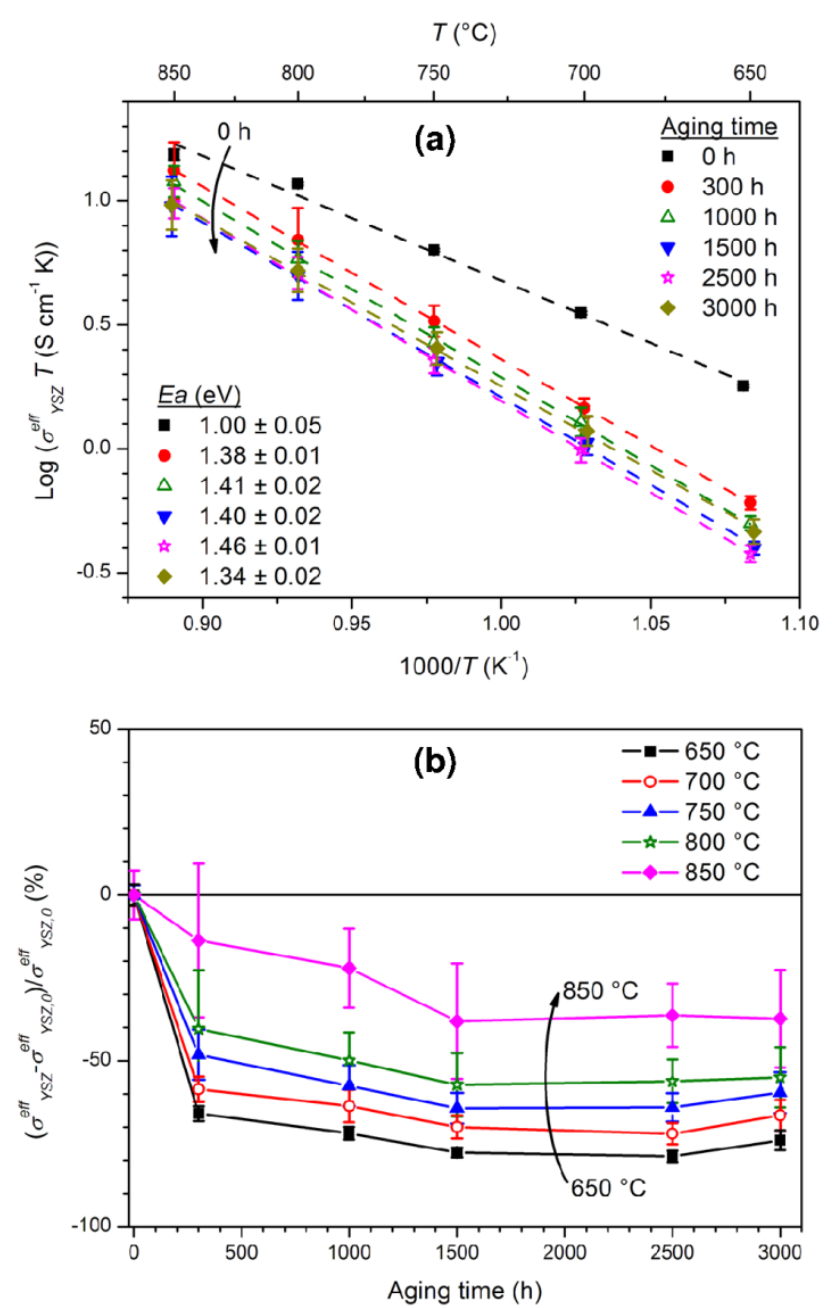

Figure 12. (Color online) (a) Arrhenius plot and (b) relative percentage variation of conductivity values of the YSZ network for LSM-YSZ cathodes after being aged at $900{ }^{\circ} \mathrm{C}$ in humidified air. The arrows represent the direction of increasing aging time in (a) and of increasing temperature in (b). 

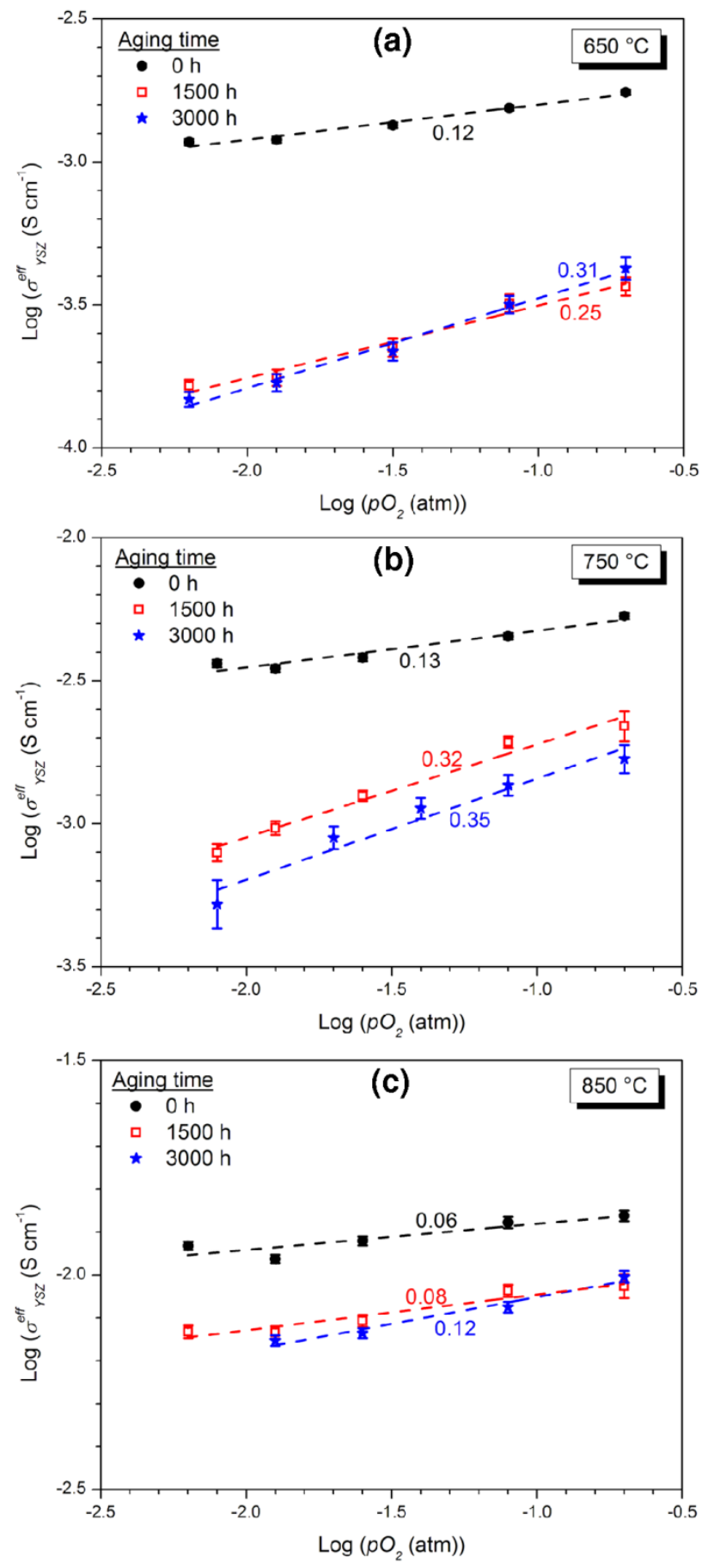

Figure 13. (Color online) Dependence on $\mathrm{pO}_{2}$ of conductivity values of the YSZ network at (a) $650{ }^{\circ} \mathrm{C}$, (b) $750{ }^{\circ} \mathrm{C}$ and (c) $850^{\circ} \mathrm{C}$ for LSM-YSZ cathodes after being aged at $900{ }^{\circ} \mathrm{C}$ in humidified air. 

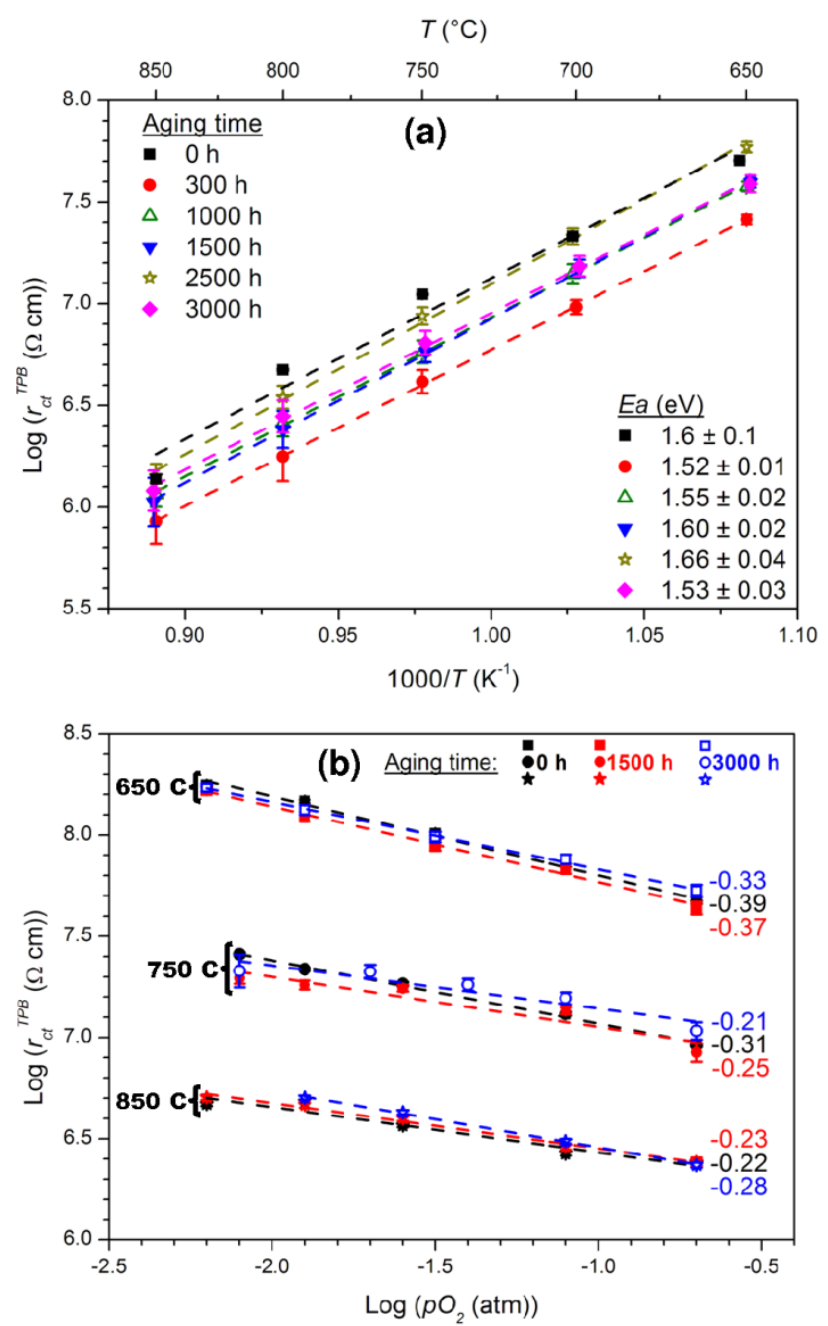

Figure 14. (Color online) (a) Arrhenius plot and (b) dependence on $\mathrm{pO}_{2}$ of the TPB specific charge transfer resistance values for LSM-YSZ cathodes after being aged at $900{ }^{\circ} \mathrm{C}$ in humidified air. 


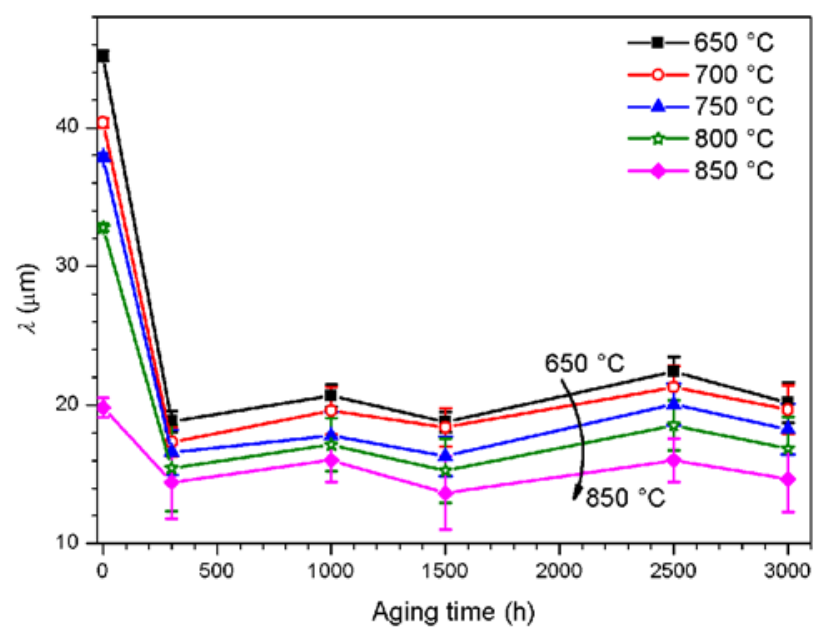

Figure 15. (Color online) Characteristic length $\lambda$ as a function of time for LSM-YSZ cathodes after being aged at $900{ }^{\circ} \mathrm{C}$ in humidified air. The arrow represents the direction of increasing temperature. 

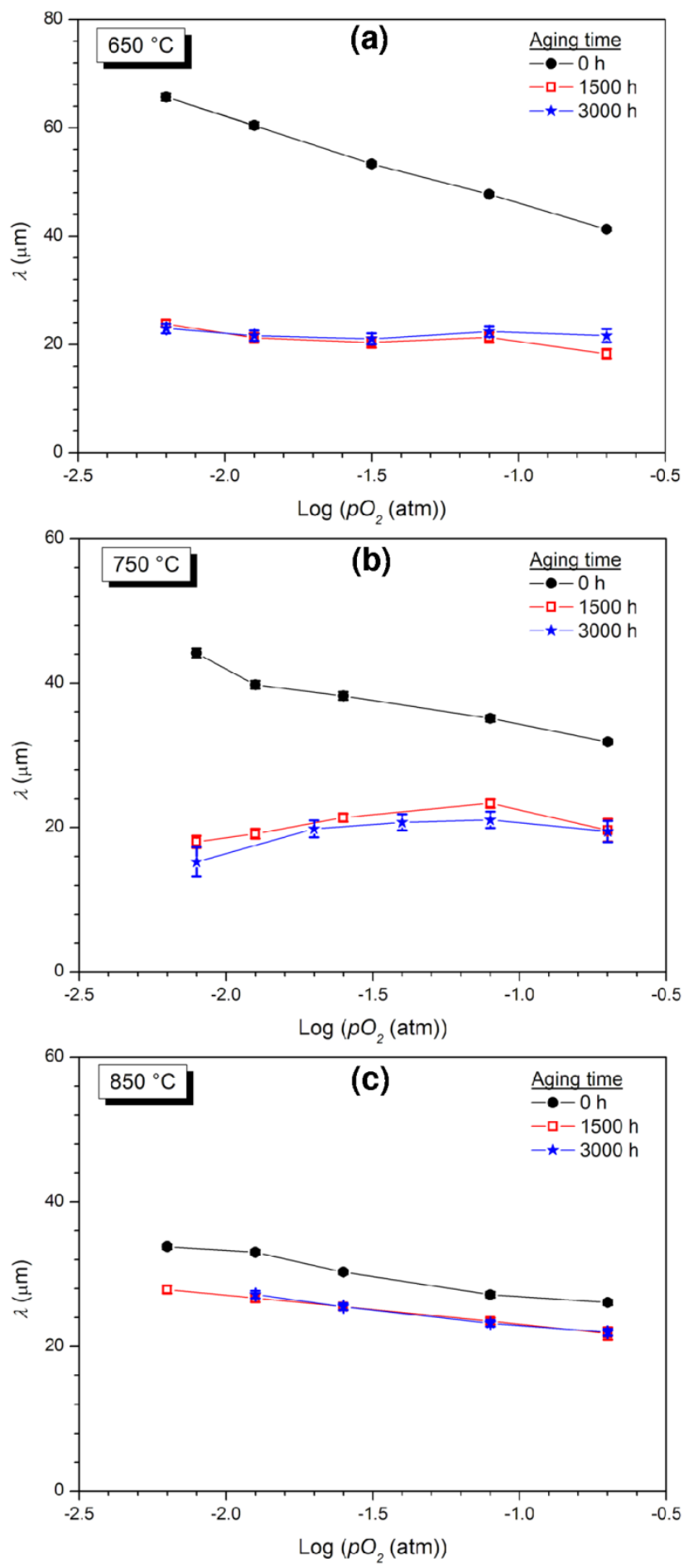

Figure 16. (Color online) Dependence of the characteristic length $\lambda$ on $p \mathrm{O}_{2}$ at (a) $650{ }^{\circ} \mathrm{C}$, (b) $750{ }^{\circ} \mathrm{C}$ and (c) $850{ }^{\circ} \mathrm{C}$ for LSM-YSZ cathodes after being aged at $900{ }^{\circ} \mathrm{C}$ in humidified air. 


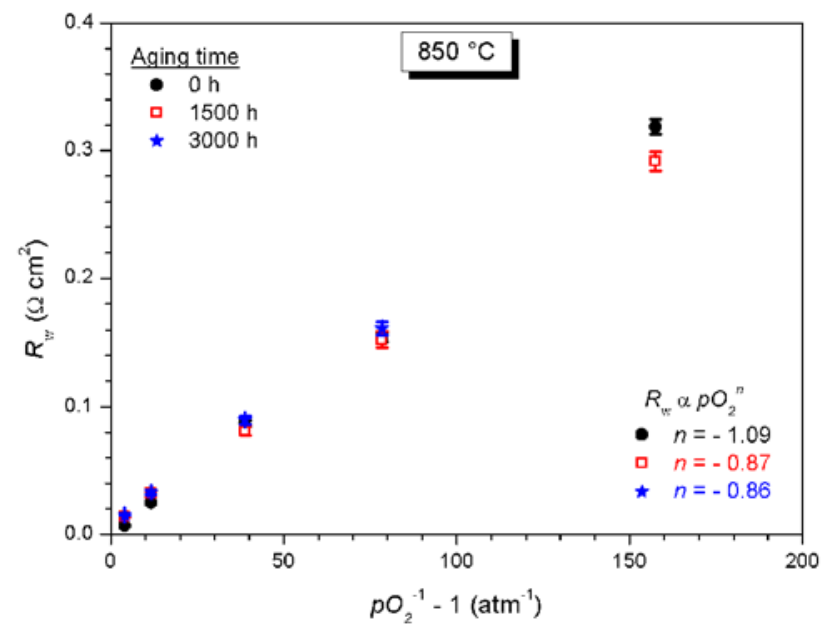

Figure 17. (Color online) Dependence on $p \mathrm{O}_{2}$ of $R_{w}$ values at $850{ }^{\circ} \mathrm{C}$ for LSM-YSZ cathodes after being aged at $900{ }^{\circ} \mathrm{C}$ in humidified air.

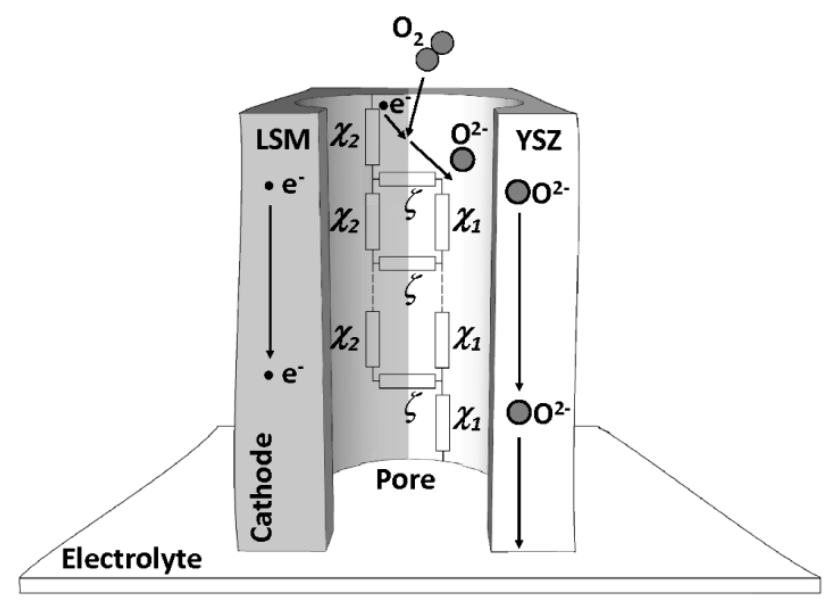

Figure A1. Simplified sketch depicting a porous LSM-YSZ composite cathode and the corresponding transmission line model. ${ }^{14-15} \chi_{1}$ represents the oxide ion conduction through YSZ, $\chi_{2}$ represents the electron conduction through LSM and $\zeta$ represents the charge transfer between them. 